\title{
EFEITO DA IRRIGAÇÃO SOBRE O POTENCIAL FISIOLÓGICO DE SEMENTES DE SOJA EM SEMEADURA DE INVERNO ${ }^{1}$
}

\author{
JOSUÉ BISPO DA SILVA², EDSON LAZARINI, MARCO EUSTÁQUIO DE SÁ4, \\ ROBERVAL DAITON VIEIRA ${ }^{5}$
}

\begin{abstract}
RESUMO - Período seco e temperaturas amenas são condições climáticas ideais durante a maturação e colheita de sementes de soja. O objetivo foi verificar o efeito da irrigação no período pós-maturidade fisiológica, sobre o potencial fisiológico de sementes de soja semeadas no inverno. A disposição dos tratamentos seguiu esquema fatorial envolvendo três cultivares (IAC-19, Conquista e IAC 8-2) e duas épocas de interrupção da irrigação (início do estádio $\mathrm{R}_{7}$ e irrigação até 14 dias após $\mathrm{R}_{8}$ ). Foram feitas amostragens (colheitas) no início do estádio $\mathrm{R}_{7}, 3$, $7,10,14$ (estádio $\mathrm{R}_{8}$ ) e 28 dias após o início do estádio $\mathrm{R}_{7}$. Para as avaliações utilizaram-se os testes de germinação, de envelhecimento acelerado e de condutividade elétrica e determinouse a porcentagem de sementes manchadas e defeituosas. Nas condições em que foi realizado o experimento, concluiu-se que a irrigação após o estádio $\mathrm{R}_{7}$ não compromete e pode até melhorar o potencial fisiológico das sementes produzidas; a produção de sementes de soja em semeadura de inverno é possível em função de condições climáticas favoráveis.
\end{abstract}

Termos para indexação: Glycine max, vigor, safrinha.

\section{IRRIGATION EFFECT ON THE PHYSIOLOGICAL POTENTIAL OF SOYBEAN SEEDS IN WINTER SOWING}

\begin{abstract}
During the maturation and harvest of soybean (Glycine max (L.) Merr.) seed the ideal climatic conditions include dryness and lower temperatures. Using winter-sown (July to September) soybean we verified the effects of irrigation on the physiological quality of soybean seeds during maturity using a factorial treatment design with three varieties (IAC-19, Conquista and IAC 8-2) and two irrigation interruption times (starting at stage $\mathrm{R}_{7}$ and irrigating until 14 days after stage $\mathrm{R}_{8}$ ). The samples were taken at stage $\mathrm{R}_{7}$ and at 3 days, 7 days, 10 days, 14 days (stage $\mathrm{R}_{8}$ ) and 28 days after starting stage $\mathrm{R}_{7}$. We evaluated the percentage germination, vigor using accelerated aging and electric conductivity tests, and the percentage of spotted and imperfect seeds and found that irrigation after stage $R_{7}$ does not reduce seed quality but can improve the physiological potential of the seeds.
\end{abstract}

Index terms: early sowing, Glycine max, vigor.

${ }^{1}$ Submetido em 01/11/2009. Aceito para publicação em 26/01/2010.

${ }^{2}$ Eng. Agr., Prof. Adjunto, Centro de Ciências Biológicas e da Natureza, UFAC, BR 364, km 04, 69915-900, Rio Branco, AC. josuebispo@bol.com.br.

${ }^{3}$ Eng. Agr., Livre Docente, Departamento de Fitotecnia, Economia e Sociologia Rural, UNESP, Campus de Ilha Solteira, SP, 15385-000.
${ }^{4}$ Eng. Agr., Prof. Titular, Departamento de Fitotecnia, Economia e Sociologia Rural, UNESP, Campus de Ilha Solteira.

${ }^{5}$ Eng. Agr., Prof. Titular, Departamento de Produção Vegetal, UNESP, Campus de Jaboticabal, SP. 


\section{INTRODUÇÃO}

Em razão de possuir características fisiológicas de sensibilidade à duração do período luminoso e temperatura, e devido às condições climáticas reinantes no Brasil, a soja é semeada nos meses de outubro e novembro, com colheita entre fevereiro e abril. As sementes produzidas apresentam, muitas vezes, índices insatisfatórios de qualidades fisiológica e sanitária, fato que pode determinar a impossibilidade de utilização em semeadura no ano seguinte.

O potencial fisiológico da semente influencia o comportamento durante o período de armazenamento e o desempenho destas em campo, sendo expresso pela longevidade, germinação e vigor (Rosseto e Marcos Filho, 1995; Oliveira, 1997; Rodo et al., 2000). Quando em nível adequado, pode apresentar reflexo direto no resultado final da cultura ao proporcionar uniformidade de população, alto vigor das plantas, ausência de patógenos transmitidos pelas sementes e, consequentemente, maior produtividade (Bittencourt, 1999; Kolchinski et al., 2005).

$\mathrm{Na}$ maturação fisiológica o potencial de desempenho das sementes é máximo; nesse estádio, o teor de água ao redor de 50\% (Jacinto e Carvalho, 1974) torna inviável a colheita mecânica, que passa a ser exeqüível quando se reduz para 1519\% (Henning e França Neto, 1993; Embrapa, 1999).

Em semeaduras de soja na época tradicional (outubro/ novembro), as sementes permanecem no campo após a maturidade fisiológica e até o momento de colheita e, por conseguinte, sujeitas ao ataque de pragas, de doenças e às adversidades ambientais. Chuva, orvalho e alta umidade relativa do ar nessa fase promovem absorção de água pelas sementes e, condições subsequentes de baixa umidade relativa e períodos ensolarados reduzem o teor de água. Como consequência das modificações no tamanho e no teor de água das sementes, podem ocorrer rachaduras e enrugamento no tegumento que, além de tornar as sementes mais permeáveis à entrada de água, portanto, à deterioração por umidade, salientam o dano causado por percevejo e favorecem o estabelecimento e desenvolvimento de fungos (Vieira et al., 1982; França Neto, 1984; Ahrens e Peske, 1994; Santos et al., 1996).

Épocas de semeadura distintas da tradicional têm sido estudadas visando rotação de culturas e melhor aproveitamento da terra. Assim, em regiões onde não ocorrem temperaturas baixas o suficiente para limitar o desenvolvimento da soja durante o outono e inverno e sendo possível a suplementação hídrica através da irrigação, torna-se possível o cultivo da soja. Nesse sentido, Motta et al. (2002) enfatizam que existe grande variabilidade entre as cultivares com relação à sensibilidade à época de semeadura e a mudanças na região de cultivo (latitudes), o que, segundo Peixoto et al. (2000), justifica os ensaios regionais de avaliação de cultivares de soja, realizados em épocas diferentes.

Nestas condições, os períodos de maturação e de colheita coincidem com condições climáticas favoráveis, ou seja, temperaturas amenas e baixa umidade relativa do ar. Assim as sementes produzidas apresentam potencial fisiológico e qualidade sanitária superiores como foram comprovados por diversos pesquisadores (Marcos Filho et al., 1984; Tragnago e Bonetti, 1984; Nakagawa et al., 1986; Medina et al., 1997; Braccini et al., 2003; Silva et al., 2007).

Embora no final da safra de 2004/2005 o vazio sanitário determinou a ausência do cultivo de soja nos meses de julho a setembro para reduzir a quantidade de inóculo da ferrugem asiática (Phakopsora pachyrhizi) nos cultivos de verão (Embrapa, 2008), o objetivo dessa medida não é resolver o problema da ferrugem, mas constitui-se em uma estratégia para reduzir o inóculo nos primeiros plantios, diminuindo a possibilidade de incidência da doença no período vegetativo e, conseqüentemente, o número de aplicações de fungicidas. Portanto, trabalhos que estudem a viabilidade da condução da cultura da soja sob condições de baixa precipitação, com irrigação suplementar e fotoperíodo atuante, não deixaram de apresentar importância prática, uma vez que faltam resultados de pesquisa comprovando a influência do inóculo produzido na entressafra, além de que atualmente a única forma de evitar reduções de produtividade na presença da ferrugem é por meio da realização do controle químico (Lima et al., 2009).

A influência da irrigação para contornar o déficit hídrico, fenômeno frequentemente verificado em semeaduras no período safrinha, sobre o desenvolvimento da planta e seus efeitos na qualidade das sementes foi estudada para diferentes culturas, como milho. Galbiatti et al. (2004) verificaram que a suspensão da irrigação aos 20 dias após o florescimento não diferiu do tratamento em que a irrigação foi mantida durante todo o ciclo. Na cultura da soja, entretanto, o uso de irrigação na entressafra pode minimizar os efeitos negativos da deficiência hídrica sobre o potencial fisiológico das sementes, em especial na fase de enchimento de vagens, ou seja, no estádio $\mathrm{R}_{5}$, conforme demonstraram vários pesquisadores (Rassini e Lin, 1981; Smiciklas et al., 1989; Dornbos et al., 1989; Heatherly, 1993). Nesse sentido, Albrecht et al. (2009) observaram que algumas das cultivares avaliadas em semeadura no período 'safrinha' não produziram sementes com qualidade fisiológica no oeste do estado do Paraná, resultado atribuído à sensibilidade daqueles genótipos ao déficit hídrico associado à baixa capacidade de retenção de água do solo naquela região.

No entanto, são poucos os trabalhos sobre efeitos da 
irrigação após o estádio $R_{7}$ na cultura da soja semeada no outono-inverno. Estudos dessa natureza são importantes porque nessa época alternativa de semeadura ocorre alteração no ciclo das cultivares e a continuidade da irrigação após a maturidade fisiológica poderia atenuar reduções no rendimento da cultura, pois, segundo Krzyzanowski et al. (1993), a produtividade tem sido inferior à da época tradicional.

O objetivo do trabalho foi avaliar o efeito da irrigação sobre o potencial fisiológico de sementes de soja, após a maturidade fisiológica, em semeadura de inverno.

\section{MATERIAL E MÉTODOS}

O experimento foi desenvolvido na Fazenda de Ensino e Pesquisa da UNESP, Campus de Ilha Solteira, localizada no município de Selvíria, MS $\left(20^{\circ} 22^{\prime} \mathrm{S}, 51^{\circ} 22^{\prime} \mathrm{W}\right.$ e altitude média de $335 \mathrm{~m}$ ). O clima da região é do tipo Aw, segundo a classificação de Köeppen. A precipitação pluvial média anual é de $1370 \mathrm{~mm}$ e as temperaturas máxima e mínima registradas diariamente no posto de observação meteorológica da Fazenda de Ensino e Pesquisa, entre os meses de julho a setembro, foram de 32,4 e $19,4{ }^{\circ} \mathrm{C}$.

As cultivares IAC-19, Conquista (MG/BR-46) e IAC 8-2, caracterizadas como de ciclo médio nas semeaduras em época tradicional no Estado de São Paulo (Embrapa, 1999), foram semeadas mecanicamente, em 24 linhas com cerca de $210 \mathrm{~m}$ de comprimento, espaçadas $0,5 \mathrm{~m}$ entre si. Foram colocadas, aproximadamente, 32 sementes por metro de sulco, com germinação média de $60 \%$, o que permitiu estabelecer uma população com 360.000 plantas. ha- ${ }^{-1}$. A semeadura e a emergência de plântulas ocorreram em $7 \mathrm{e}$ 16/6/99, respectivamente. Os estádios de desenvolvimento $\left(\mathrm{R}_{7}\right.$ e $\mathrm{R}_{8}$ ) foram identificados segundo descrição de Fehr et al. (1971) e caracterizados quando $50 \%$ das plantas, no mínimo, encontravam-se com as características que os descrevem.

Os tratamentos foram dispostos em esquema fatorial e corresponderam a três cultivares e duas épocas de interrupção da irrigação: $I_{1}$ - suspensão da irrigação no início do estádio $\mathrm{R}_{7}$ e $\mathrm{I}_{2}$ - irrigação até o estádio $\mathrm{R}_{8}+14$ dias.

Para avaliar os efeitos sobre a qualidade das sementes, foram realizadas seis amostragens, correspondentes ao início do estádio $R_{7}$ e aos 3, 7, 10, 14 (estádio $R_{8}$ ) e 28 dias após o início do estádio $R_{7}$. Em cada amostragem, coletaram-se as plantas de duas linhas com dois metros de comprimento cada, em quatro repetições aleatoriamente em cada parcela.

O sistema de irrigação utilizou aspersores Plona tipo $\mathrm{ZN}-24$ com bocal $18 \times 6 \mathrm{~mm}$. As parcelas experimentais constituíram-se de 24 linhas de cada cultivar, com $24 \mathrm{~m}$ de comprimento. Como bordadura e para que ocorresse o isolamento entre os tratamentos, deixou-se um espaço de $36 \mathrm{~m}$. Portanto, em cada parcela designou-se um tratamento quanto à irrigação, sendo as repetições tomadas aleatoriamente dentro da mesma.

Durante a fase de desenvolvimento vegetativo e início dos estádios reprodutivos, a área experimental foi irrigada semanalmente, por um período de uma hora em cada tratamento. As avaliações constaram de: - teste de germinação (G): conduzido segundo protocolo contido nas Regras para Análise de Sementes (Brasil, 1992); - envelhecimento acelerado (EA): conduzido segundo protocolo da AOSA (2002); - condutividade elétrica (CE): quatro subamostras de 25 sementes de cada tratamento tiveram suas massas avaliadas em balança de precisão $(0,001 \mathrm{~g})$ e colocadas para embeber em um recipiente contendo $75 \mathrm{~mL}$ de água destilada e deionizada, sob temperatura de $24{ }^{\circ} \mathrm{C}$ por 24 horas; após este período, procedeu-se à leitura da condutividade elétrica na solução de embebição, através de um condutivímetro digital, com expressão dos resultados em $\mu \mathrm{S} . \mathrm{cm}^{-1} \cdot \mathrm{g}^{-1}$ (Vieira e Krzyzanowski, 1999); - sementes manchadas e defeituosas (SMD): após exame minucioso de 200 sementes por tratamento, em quatro repetições, foram separadas as que apresentavam manchas ou defeitos e, a seguir, determinada a porcentagem em massa em relação ao total da amostra; foram consideradas como manchadas todas as sementes que possuíam algum tipo de mancha no tegumento e defeituosas as que apresentavam depressão ou deformação na superfície (Fonseca e Sá, 2005).

$\mathrm{O}$ delineamento experimental foi inteiramente ao acaso, com quatro repetições de 50 sementes, nos testes de $\mathrm{G}$ e de EA, quatro repetições de 25 sementes no de CE e quatro repetições de 200 sementes no de SMD. Foram avaliados seis momentos de amostragem, analisados em esquema fatorial (cultivar x época de suspensão da irrigação) e as médias comparadas pelo teste de Tukey $(\mathrm{P}<0,05)$.

\section{RESULTADOS E DISCUSSÃO}

No teste de germinação, a análise de variância evidenciou diferença significativa no desempenho das sementes entre cultivares no momento de amostragem $\mathrm{R}_{7}+7$ dias, assim como entre cultivares, tratamentos e na interação entre esses fatores no momento $\mathrm{R}_{7}+28$ dias (Tabela 1). Os valores médios mostraram resultados superiores nas primeiras amostragens, com valores acima de $90 \%$ até $R_{7}+7$ dias, com redução nas amostragens seguintes, principalmente no tratamento $\mathrm{I}_{1}$ (Tabela 2).

No momento $\mathrm{R}_{7}+7$ dias, os valores médios da cultivar IAC-19 nos dois tratamentos superaram estatisticamente Conquista e IAC 8-2. Na amostragem $\mathrm{R}_{7}+28$ dias, as cultivares diferiram entre si nos valores médios dos dois 
tratamentos, com superioridade novamente para IAC19, seguida de Conquista e de IAC 8-2. No tratamento $\mathrm{I}_{1}$, IAC 8-2 mostrou-se inferior a IAC-19 e Conquista, ao passo que no tratamento $I_{2}$ não houve diferença entre as cultivares. Na comparação entre tratamentos, apenas na cultivar Conquista não houve diferença, enquanto para IAC-19 e, principalmente, IAC 8-2, verificou-se que a continuidade da irrigação até 28 dias após $R_{7}$ foi significativamente benéfica para o potencial germinativo das sementes (Tabela 2).

TABELA 1. Análise de variância para germinação, envelhecimento acelerado, condutividade elétrica e sementes manchadas e defeituosas, considerando os fatores cultivares (C) e épocas de suspensão da irrigação (I), em sementes de soja colhidas em diferentes estádios de desenvolvimento das plantas.

\begin{tabular}{|c|c|c|c|c|c|c|}
\hline \multicolumn{7}{|c|}{ Teste de Germinação } \\
\hline F.V. & $\mathrm{R}_{7}$ & $\mathrm{R}_{7}+3$ dias & $\mathrm{R}_{7}+7$ dias & $\mathrm{R}_{7}+10$ dias & $\mathrm{R}_{7}+14 \operatorname{dias}\left(\mathrm{R}_{8}\right)$ & $\mathrm{R}_{7}+28$ dias \\
\hline $\mathrm{C}$ & $0,99 \mathrm{~ns}$ & $2,79 \mathrm{~ns}$ & $8,77 * *$ & $0,53 \mathrm{~ns}$ & $0,25 \mathrm{~ns}$ & $13,90 * *$ \\
\hline I & $0,12 \mathrm{~ns}$ & $2,73 \mathrm{~ns}$ & $0,53 \mathrm{~ns}$ & $3,24 \mathrm{~ns}$ & $4,38 \mathrm{~ns}$ & $45,97 * *$ \\
\hline $\mathrm{C} * \mathrm{I}$ & $0,04 \mathrm{~ns}$ & $0,06 \mathrm{~ns}$ & $0,34 \mathrm{~ns}$ & $1,70 \mathrm{~ns}$ & $1,91 \mathrm{~ns}$ & $13,30 * *$ \\
\hline \multicolumn{7}{|c|}{ Teste de Envelhecimento Acelerado } \\
\hline $\mathrm{C}$ & $2,09 \mathrm{~ns}$ & $0,55 \mathrm{~ns}$ & $0,38 \mathrm{~ns}$ & $18,21 * *$ & $1,40 \mathrm{~ns}$ & $6,12 * *$ \\
\hline I & $5,45^{*}$ & $1,52 \mathrm{~ns}$ & $3,77 \mathrm{~ns}$ & $9,02 * *$ & $0,10 \mathrm{~ns}$ & $53,32 * *$ \\
\hline $\mathrm{C} * \mathrm{I}$ & $15,78 * *$ & $1,82 \mathrm{~ns}$ & $2,82 \mathrm{~ns}$ & $1,70 \mathrm{~ns}$ & $0,16 \mathrm{~ns}$ & $3,26 \mathrm{~ns}$ \\
\hline \multicolumn{7}{|c|}{ Teste de Condutividade Elétrica } \\
\hline $\mathrm{C}$ & $1,95 \mathrm{~ns}$ & $7,62 * *$ & $2,70 \mathrm{~ns}$ & $9,33 * *$ & $1,66 \mathrm{~ns}$ & $1,44 \mathrm{~ns}$ \\
\hline I & $1,80 \mathrm{~ns}$ & $0,00 \mathrm{~ns}$ & $0,23 \mathrm{~ns}$ & $0,95 \mathrm{~ns}$ & $2,00 \mathrm{~ns}$ & $17,73 * *$ \\
\hline $\mathrm{C} * \mathrm{I}$ & $3,20 \mathrm{~ns}$ & $4,30 *$ & $3,44 \mathrm{~ns}$ & $0,33 \mathrm{~ns}$ & $0,26 \mathrm{~ns}$ & $0,24 \mathrm{~ns}$ \\
\hline \multicolumn{7}{|c|}{ Sementes manchadas e defeituosas } \\
\hline $\mathrm{C}$ & $10,03 * *$ & $45,53 * *$ & $32,08 * *$ & $20,37 * *$ & $3,47 \mathrm{~ns}$ & $5,93 *$ \\
\hline I & $9,41 * *$ & $50,77 * *$ & $21,97 * *$ & $0,87 \mathrm{~ns}$ & $8,92 * *$ & $34,77 * *$ \\
\hline $\mathrm{C} * \mathrm{I}$ & $6,01 *$ & $52,47 * *$ & $1,83 \mathrm{~ns}$ & $2,19 \mathrm{~ns}$ & $12,35 * *$ & $11,14 * *$ \\
\hline
\end{tabular}

**: significativo ao nível de $1 \%$ de probabilidade $(\mathrm{p}<0,01)$; : significativo ao nível de $5 \%$ de probabilidade $(0,01 \leq \mathrm{p}<0,05)$; ns: não significativo (p $\geq$ $0,05)$.

Em todas as amostragens, o prolongamento da irrigação $\left(\mathrm{I}_{2}\right)$ propiciou a formação de sementes com germinação igual ou maior que $80 \%$ em todas as cultivares, valor mínimo considerado adequado para a semeadura no Estado de Mato Grosso do Sul em época convencional (Embrapa, 1993) e para sementes certificadas de primeira e segunda geração (Brasil, 2005). Desempenho semelhante foi encontrado por Silva et al. (2007) em 32 cultivares de soja, entre elas IAC-19, Conquista e IAC 8-2 semeadas na mesma região e época.

No teste de envelhecimento acelerado, houve diferença de vigor para tratamentos e interação significativa entre cultivares e tratamentos na amostragem $\mathrm{R}_{7}$ e para cultivares e tratamentos em $R_{7}+10$ dias e $R_{7}+28$ dias (Tabela 1$)$. Em $\mathrm{R}_{7}$, o prolongamento da irrigação foi indiferente para o vigor da semente de IAC-19 e prejudicial para a de Conquista, enquanto que para a de IAC 8-2 foi benéfico (Tabela 3). Essa resposta distinta de vigor das sementes das cultivares aos tratamentos pode ser devida a fatores genéticos, inerentes a cada genótipo. No entanto, a comparação das médias entre tratamentos mostrou redução do vigor no prolongamento da irrigação após $\mathrm{R}_{7}$. Na amostragem $\mathrm{R}_{7}+10$ dias as cultivares IAC-19 e Conquista superaram IAC 8-2 e, na comparação entre tratamentos, $\mathrm{I}_{2}$ superou $\mathrm{I}_{1}$. Em $\mathrm{R}_{7}+28$ dias a cultivar IAC19 superou IAC 8-2 e igualou-se a Conquista. Novamente, o tratamento $\mathrm{I}_{2}$ foi superior a $\mathrm{I}_{1}$. 
TABELA 2. Teste de germinação (\%): dados médios, considerando cultivares e épocas de suspensão da irrigação ( $I_{1}$ e $\left.I_{2}\right)$, em sementes de soja colhidas em diferentes estádios de desenvolvimento das plantas.

\begin{tabular}{|c|c|c|c|c|c|}
\hline \multirow{2}{*}{ Momentos de amostragem } & & \multicolumn{3}{|c|}{ Cultivares } & \multirow[b]{2}{*}{ Média } \\
\hline & & IAC 19 & Conquista & IAC $8-2$ & \\
\hline & & \multicolumn{4}{|c|}{ 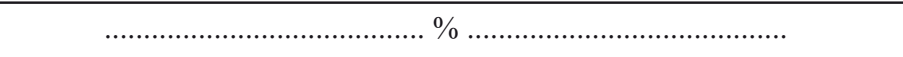 } \\
\hline \multirow{3}{*}{ R7 } & $\mathrm{I}_{1}$ & 94 & 94 & 91 & 93 \\
\hline & $1_{2}$ & 94 & 92 & 93 & 93 \\
\hline & Média & 94 & 92 & 93 & - \\
\hline \multirow{3}{*}{$\mathrm{R}_{7}+3$ dias } & $\mathrm{I}_{1}$ & 92 & 86 & 93 & 90 \\
\hline & $1_{2}$ & 96 & 91 & 96 & 94 \\
\hline & Média & 94 & 88 & 95 & - \\
\hline \multirow{3}{*}{$\mathrm{R}_{7}+7$ dias } & $\mathrm{I}_{1}$ & 95 & 91 & 91 & 92 \\
\hline & $1_{2}$ & 97 & 90 & 92 & 93 \\
\hline & Média & $96 \mathrm{~A}$ & $90 \mathrm{~B}$ & $91 \mathrm{~B}$ & - \\
\hline \multirow{3}{*}{$\mathrm{R}_{7}+10$ dias } & $\mathrm{I}_{1}$ & 80 & 82 & 84 & 82 \\
\hline & $1_{2}$ & 91 & 91 & 81 & 87 \\
\hline & Média & 85 & 86 & 82 & - \\
\hline \multirow{3}{*}{$\mathrm{R}_{7}+14 \operatorname{dias}\left(\mathrm{R}_{8}\right)$} & $\mathrm{I}_{1}$ & 78 & 73 & 74 & 75 \\
\hline & $1_{2}$ & 76 & 88 & 84 & 83 \\
\hline & Média & 77 & 80 & 79 & - \\
\hline \multirow{3}{*}{$\mathrm{R}_{7}+28$ dias } & $\mathrm{I}_{1}$ & $79 \mathrm{Ab}$ & $71 \mathrm{Aa}$ & $43 \mathrm{Bb}$ & $64 \mathrm{~b}$ \\
\hline & $1_{2}$ & $90 \mathrm{a}$ & $80 \mathrm{a}$ & $86 a$ & $85 \mathrm{a}$ \\
\hline & Média & $84 \mathrm{~A}$ & $75 \mathrm{~B}$ & $64 \mathrm{C}$ & - \\
\hline
\end{tabular}

Médias seguidas pelas mesmas letras, maiúsculas nas linhas e minúsculas nas colunas, não diferem entre si pelo Teste de Tukey (P $\leq 0,05)$.

Nesse teste as sementes mostraram a mesma tendência observada no teste de germinação, ou seja, nas primeiras amostragens foram mais vigorosas e, quando houve diferença entre os tratamentos, foi favorável ao tratamento $\mathrm{I}_{2}$, com exceção da primeira amostragem na cultivar Conquista e na comparação entre cultivares, quando a cultivar IAC 82 apresentou o menor vigor, principalmente nas últimas amostragens (Tabela 2).

Considera-se que lotes de sementes de soja com germinação superior a $80 \%$ no teste de envelhecimento acelerado têm possibilidade de emergência adequada de plântulas em campo, sob condições de ambiente aquém do ideal (Egli e TeKrony, 1995), como possivelmente ocorreu no presente trabalho. Mesmo assim, as três cultivares avaliadas apresentaram desempenho satisfatório nas três primeiras amostragens. Nos trabalhos de Silva et al. (2007), o desempenho das sementes das cultivares Conquista e IAC 8-2 no teste de envelhecimento acelerado foi igualmente satisfatório, com valores de 84 e $95 \%$, ao passo que IAC-19 apresentou $79 \%$ de germinação, valor próximo ao desejável.
No teste de condutividade elétrica houve diferença significativa entre cultivares e na interação entre eles e os tratamentos na amostragem $\mathrm{R}_{7}+3$ dias, entre cultivares em $\mathrm{R}_{7}+10$ dias e entre tratamentos em $\mathrm{R}_{7}+28$ dias (Tabela 1 ). No tratamento $\mathrm{I}_{1}$ da amostragem $\mathrm{R}_{7}+3$ dias, a cultivar IAC 8-2 mostrou valor superior ao das outras duas e, em relação aos tratamentos, foi também superior em $\mathrm{I}_{1}$, o que indica potencial fisiológico inferior (Tabela 4).

Sementes de soja com condutividade elétrica até 60 $70 \mu \mathrm{S} . \mathrm{cm}^{-1} \cdot \mathrm{g}^{-1}$ são consideradas de alto vigor, enquanto 70 $80 \mu \mathrm{S} . \mathrm{cm}^{-1} \cdot \mathrm{g}^{-1}$ são valores com tendência para médio vigor (AOSA, 2002), embora Vieira et al. (2004) considerem que sementes com valores de até $90 \mu \mathrm{S} . \mathrm{cm}^{-1} . \mathrm{g}^{-1}$ podem apresentar desempenho satisfatório em condições de campo abaixo do ideal ou, segundo Vieira et al. (1999a,b), até mesmo com valores de $100-110 \mu \mathrm{S} . \mathrm{cm}^{-1} \cdot \mathrm{g}^{-1}$, caso as condições ambientais sejam adequadas. Sendo assim, nas primeiras amostragens, com exceção de IAC 8-2 em I $\mathrm{I}_{1}$ e independente da cultivar e do tratamento, os valores de condutividade elétrica indicaram sementes de alto vigor, decaindo esta qualidade 
nas amostragens mais tardias, ou seja, a partir de $R_{7}$ + 10 dias. Já nos trabalhos de Silva et al. (2007), essas cultivares foram classificadas como sendo de vigor baixo ou intermediário.

TABELA 3. Teste de envelhecimento acelerado (\%): dados médios, considerando cultivares e épocas de suspensão da irrigação $\left(I_{1}\right.$ e $\left.I_{2}\right)$, em sementes de soja colhidas em diferentes estádios de desenvolvimento das plantas.

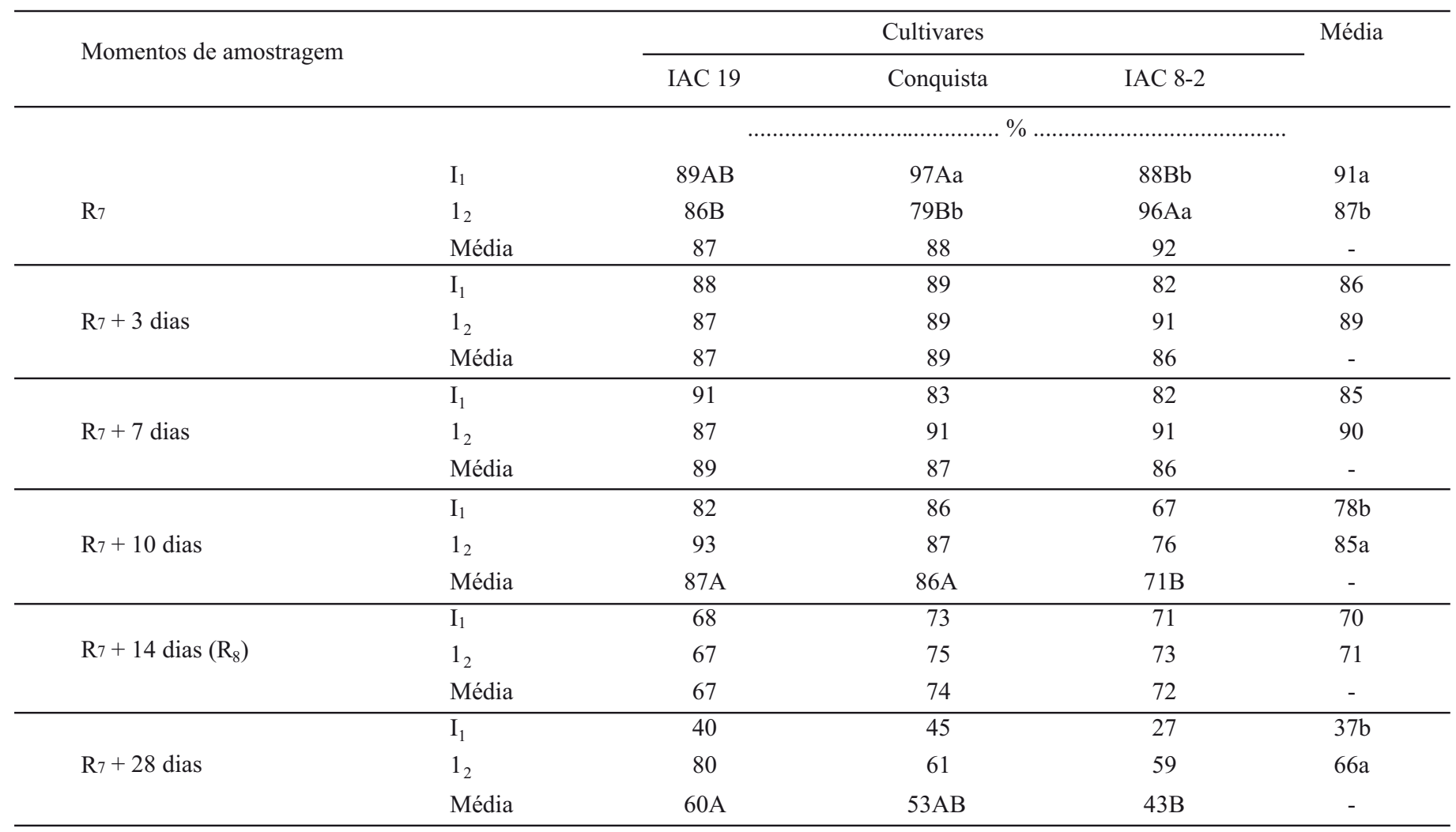

Médias seguidas pelas mesmas letras, maiúsculas nas linhas e minúsculas nas colunas, não diferem entre si pelo Teste de Tukey (P $\leq 0,05)$.

$\mathrm{Na}$ avaliação de sementes manchadas e defeituosas, houve diferença entre cultivares, tratamentos e o efeito da interação entre esses fatores foi também significativo nos momentos $\mathrm{R}_{7}, \mathrm{R}_{7}+3$ dias e $\mathrm{R}_{7}+28$ dias. $\mathrm{Em}_{7}+7$ dias diferiram cultivares e tratamentos, em $\mathrm{R}_{7}+10$ dias diferiram cultivares e em $R_{7}+14$ dias diferiram tratamentos e a interação entre cultivares e tratamentos (Tabela 1).

Nesse parâmetro, não houve concordância entre as variáveis. Apenas observa-se que para a cultivar IAC 8-2, no tratamento $\mathrm{I}_{1}$, o percentual de sementes manchadas e enrugadas foi mais alto (Tabela 5), podendo ser este um dos motivos das sementes de menor vigor, como verificado nos testes de envelhecimento acelerado e condutividade elétrica. A associação da qualidade física da semente com seu desempenho germinativo foi verificada por Vieira et al. (1991) e Crusciol et al. (2002), ou seja, as cultivares com menor percentual de sementes deformadas mostraram-se mais vigorosas.

De maneira geral, o potencial fisiológico das sementes nas primeiras amostragens, ou seja, na maturidade fisiológica ou logo após, foi superior, concordando com a afirmação de Tekrony et al. (1980) de que na maturação fisiológica o vigor e o potencial de germinação das sementes é máximo, com mínima deterioração.

Entre os tratamentos relativos à irrigação, verificou-se que $\mathrm{I}_{2}$ proporcionou menor percentual de sementes manchadas e de melhor qualidade, conforme mostrado nos testes de germinação, envelhecimento acelerado e condutividade elétrica, evidenciando que as irrigações realizadas com freqüência após $\mathrm{R}_{7}$ trouxeram ganhos à qualidade das sementes.

Os dados da literatura referentes aos efeitos da irrigação na qualidade de sementes mostram a importância 
TABELA 4. Teste de condutividade elétrica $\left(\mu \mathrm{S}_{\mathrm{c}} \mathrm{cm}^{-1} \cdot \mathrm{g}^{-1}\right)$ : dados médios, considerando cultivares e épocas de suspensão da irrigação $\left(I_{1}\right.$ e $\left.I_{2}\right)$, em sementes de soja colhidas em diferentes estádios de desenvolvimento das plantas.

\begin{tabular}{|c|c|c|c|c|c|}
\hline \multirow{2}{*}{ Momentos de amostragem } & & \multicolumn{3}{|c|}{ Cultivares } & \multirow{2}{*}{ Média } \\
\hline & & IAC 19 & Conquista & IAC 8-2 & \\
\hline & & & $\ldots \ldots . \mathrm{S}$ & (2) & \\
\hline \multirow{3}{*}{$\mathrm{R}_{7}$} & $\mathrm{I}_{1}$ & 47 & 59 & 59 & 55 \\
\hline & $1_{2}$ & 59 & 59 & 57 & 58 \\
\hline & Média & 53 & 59 & 58 & - \\
\hline \multirow{3}{*}{$\mathrm{R}_{7}+3$ dias } & $\mathrm{I}_{1}$ & $50 \mathrm{~B}$ & $63 \mathrm{~B}$ & $88 \mathrm{Aa}$ & $67 \mathrm{a}$ \\
\hline & $1_{2}$ & 58 & 76 & $67 \mathrm{a}$ & $67 \mathrm{a}$ \\
\hline & Média & $54 \mathrm{~B}$ & $70 \mathrm{~A}$ & $78 \mathrm{~A}$ & - \\
\hline \multirow{3}{*}{$\mathrm{R}_{7}+7$ dias } & $\mathrm{I}_{1}$ & 56 & 67 & 84 & 69 \\
\hline & $1_{2}$ & 75 & 69 & 72 & 71 \\
\hline & Média & 65 & 67 & 78 & - \\
\hline \multirow{3}{*}{$\mathrm{R}^{7}+10$ dias } & $\mathrm{I}_{1}$ & 80 & 79 & 109 & 89 \\
\hline & $1_{2}$ & 78 & 76 & 97 & 84 \\
\hline & Média & $79 \mathrm{~B}$ & $78 \mathrm{~B}$ & $103 \mathrm{~A}$ & - \\
\hline \multirow{3}{*}{$\mathrm{R}_{7}+14 \operatorname{dias}\left(\mathrm{R}_{8}\right)$} & $\mathrm{I}_{1}$ & 95 & 89 & 104 & 96 \\
\hline & $1_{2}$ & 91 & 84 & 91 & 89 \\
\hline & Média & 93 & 86 & 98 & - \\
\hline \multirow{3}{*}{$\mathrm{R}_{7}+28$ dias } & $\mathrm{I}_{1}$ & 131 & 113 & 138 & $127 \mathrm{a}$ \\
\hline & $1_{2}$ & 84 & 82 & 97 & $87 \mathrm{~b}$ \\
\hline & Média & 108 & 97 & 117 & - \\
\hline
\end{tabular}

Médias seguidas pelas mesmas letras, maiúsculas nas linhas e minúsculas nas colunas, não diferem entre si pelo Teste de Tukey (P $\leq 0,05)$.

desta prática na fase de maior acúmulo de matéria seca (Rassini e Lin, 1981; Smiciklas et al., 1989; Heatherly, 1993). No entanto, o objetivo do presente estudo foi avaliar o efeito da irrigação após o estádio $\mathrm{R}_{7}$, ou seja, após a semente já formada. A produção de sementes com potencial fisiológico semelhante ou superior com o prolongamento da irrigação após $\mathrm{R}_{7}$ foi possível devido, provavelmente, às condições climáticas da ocasião, como baixa umidade relativa e ausência de precipitação na fase de maturação. Nos trabalhos de Lima et al. (2009), as sementes da cultivar IAC-19 semeada em época de safrinha (março) apresentaram potencial fisiológico inferior às do presente trabalho, conforme resultados dos testes de germinação $(83,8 \%)$, envelhecimento acelerado $(75,8 \%)$ e condutividade elétrica $\left(148,56 \mu \mathrm{S} . \mathrm{cm}^{-1} \cdot \mathrm{g}^{-1}\right)$; durante a condução desse experimento, no entanto, as plantas não foram submetidas à irrigação.

A umidade das sementes sofreu alteração com as irrigações realizadas no tratamento $\mathrm{I}_{2}$, embora não tenha ultrapassado 13\%, mas rapidamente declinou devido, possivelmente, à baixa umidade relativa do ar, não proporcionando, portanto, efeito negativo na qualidade das sementes. A necessidade de temperaturas amenas, baixa umidade relativa do ar e ausência de chuvas ou orvalho durante a fase de maturação para produção de sementes com elevado potencial fisiológico é um fator de alta relevância, conforme destacado por Yalich e Cregan (1987), Krzyzanowski et al. (1993) e Ahrens e Peske (1994).

\section{CONCLUSÕES}

A irrigação após o estádio $R_{7}$ e até $R_{8}$ não compromete e pode melhorar o potencial fisiológico das sementes produzidas, quando presente condições climáticas de baixa umidade relativa do ar, temperaturas amenas e ausência de chuvas.

A produção de sementes de soja em semeadura de inverno é possível na ocorrência de condições climáticas favoráveis, necessitando, no entanto, o aporte de um suprimento hídrico e controle intensivo da ferrugem. 
TABELA 5. Sementes manchadas e defeituosas (\% em massa): dados médios, considerando cultivares e épocas de suspensão da irrigação $\left(I_{1}\right.$ e $\left.I_{2}\right)$, em sementes de soja colhidas em diferentes estádios de desenvolvimento das plantas.

\begin{tabular}{|c|c|c|c|c|c|}
\hline \multirow{2}{*}{ Momentos de amostragem } & & \multicolumn{3}{|c|}{ Cultivares } & \multirow{2}{*}{ Média } \\
\hline & & IAC 19 & Conquista & IAC $8-2$ & \\
\hline & & \multicolumn{4}{|c|}{ 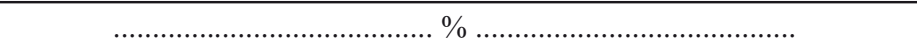 } \\
\hline \multirow{3}{*}{$\mathrm{R}_{7}$} & $\mathrm{I}_{1}$ & $7 \mathrm{Bb}$ & $5 \mathrm{~B}$ & $12 \mathrm{~A}$ & $8 b$ \\
\hline & $1_{2}$ & $14 \mathrm{Aa}$ & $8 \mathrm{~B}$ & $11 \mathrm{AB}$ & $11 \mathrm{a}$ \\
\hline & Média & $10 \mathrm{~A}$ & $7 \mathrm{~B}$ & $12 \mathrm{~A}$ & - \\
\hline \multirow{3}{*}{$\mathrm{R}_{7}+3$ dias } & $\mathrm{I}_{1}$ & $7 \mathrm{Bb}$ & $8 \mathrm{Ba}$ & $20 \mathrm{Aa}$ & $12 \mathrm{a}$ \\
\hline & $1_{2}$ & $10 \mathrm{Aa}$ & $5 \mathrm{Bb}$ & $7 \mathrm{ABb}$ & $7 b$ \\
\hline & Média & $8 \mathrm{~B}$ & $6 \mathrm{C}$ & $14 \mathrm{~A}$ & - \\
\hline \multirow{3}{*}{$\mathrm{R}_{7}+7$ dias } & $\mathrm{I}_{1}$ & 6 & 11 & 12 & $10 \mathrm{a}$ \\
\hline & $1_{2}$ & 4 & 7 & 10 & $7 b$ \\
\hline & Média & $5 \mathrm{~B}$ & $9 \mathrm{~A}$ & $11 \mathrm{~A}$ & - \\
\hline \multirow{3}{*}{$\mathrm{R}_{7}+10$ dias } & $\mathrm{I}_{1}$ & 11 & 7 & 12 & 10 \\
\hline & $1_{2}$ & 8 & 5 & 14 & 9 \\
\hline & Média & $10 \mathrm{~B}$ & $6 \mathrm{C}$ & $13 \mathrm{~A}$ & - \\
\hline \multirow{3}{*}{$\mathrm{R}_{7}+14 \operatorname{dias}\left(\mathrm{R}_{8}\right)$} & $\mathrm{I}_{1}$ & $8 \mathrm{~B}$ & 10B & $14 \mathrm{Aa}$ & $11 \mathrm{a}$ \\
\hline & $1_{2}$ & 10 & 7 & $8 b$ & $9 b$ \\
\hline & Média & 9 & 9 & 11 & - \\
\hline \multirow{3}{*}{$\mathrm{R}_{7}+28$ dias } & $\mathrm{I}_{1}$ & $10 \mathrm{Ba}$ & 9B & $17 \mathrm{Aa}$ & $12 \mathrm{a}$ \\
\hline & $1_{2}$ & $4 \mathrm{Bb}$ & $9 \mathrm{~A}$ & $6 \mathrm{ABb}$ & $6 \mathrm{~b}$ \\
\hline & Média & $7 \mathrm{~B}$ & $9 \mathrm{AB}$ & $11 \mathrm{~A}$ & - \\
\hline
\end{tabular}

Médias seguidas pelas mesmas letras, maiúsculas nas linhas e minúsculas nas colunas, não diferem entre si pelo Teste de Tukey (P $\leq 0,05)$.

\section{REFERÊNCIAS}

AHRENS, D.C.; PESKE, S.T. Flutuações de umidade e qualidade em sementes de soja após a maturação fisiológica. Revista Brasileira de Sementes, v.16, n.2, p.107-110, 1994.

ALBRECHT, L.P.; BRACCINI, A.L.; ÁVILA, M.R.; SCAPIM, C.A.; BARBOSA, M.B.; STÜLP, M. Sementes de soja produzidas em época de safrinha na região oeste do estado do Paraná. Acta Scientiarum.Agronomy, v.31, n.1, p.121-127, 2009.

ASSOCIATION OF OFFICIAL SEED ANALYSTS-AOSA. Seed vigor testing handbook. Lincoln: AOSA, 2002. 105p. (Contribuition, 32).

BITTENCOURT, S.R.M. Teste de envelhecimento acelerado associado ao teste de tetrazólio para avaliação do vigor de sementes de milho. 1999. 151f. (Tese Doutorado) - Universidade Estadual Paulista, Jaboticabal.
BRACCINI, A.L.; MOTA, I.S.; SCAPIM, C.A.; BRACCINI, M.C.L.; ÁVILA, M.R.; SCHUAB, S.R.P. Semeadura da soja no período de safrinha: potencial fisiológico e sanidade das sementes. Revista Brasileira de Sementes, v.25, n.1, p.76$86,2003$.

BRASIL. Instrução Normativa n.25, de 16 de dezembro de 2005: padrões para produção e comercialização de sementes de soja. Diário Oficial da União, n.243 de 20 de dezembro de 2005, Brasília, 20 de dezembro de 2005. Seção 1, p.2.

BRASIL. Ministério da Agricultura e Reforma Agrária. Secretaria Nacional de Defesa Agropecuária. Departamento Nacional de Defesa Vegetal. Coordenação de Laboratório Vegetal. Regras para análise de sementes. Brasília, DF, 1992. 365p.

CRUSCIOL, C.A.C.; LAZARINI, E.; BUZO, C.L.; SÁ, M.E. Produção e qualidade fisiológica de sementes de soja avaliadas na semeadura de inverno. Scientia Agricola, v.59, n.1, p.79-86, 2002.

DORNBOS, D.L.; MULLEN, R.G.; SHIBLES, R.M. Drought 
stress effects during seed-fill on soybean seed germination and vigor. Crop Science, v.29, n.2, p.476-480, 1989.

EGLI, D.B.; TEKRONY, D.M. Soybean seed germination, vigor and field emergence. Seed Science and Technology, v.23, n.3, p.595-607, 1995.

EMPRESA BRASILEIRA DE PESQUISA AGROPECUÁRIA. Serviço de produção de sementes básicas. Padrões estaduais de sementes. Brasília, DF: EMBRAPA-DID, 1993. p.35-37.

EMPRESA BRASILEIRA DE PESQUISA AGROPECUÁRIA.Centro Nacional de Pesquisa de Soja. Recomendações para a cultura da soja na região central do Brasil - 1999/2000. Londrina, 1999. 226p. (EMBRAPA. CNPSo. Documentos, 132).

FEHR, W.R.; CAVINESS, C.E.; BEURMOOD, D.T.; PENNINGTON, J.S. Stage of development descriptions for soybeans [Glycine $\max$ (L.) Merrill]. Crop Science, v.11, n.6, p.929-931, 1971.

FONSECA, N.R.; SÁ, M.E. Qualidade física e fisiológica da semente de dois cultivares de soja em função de doses de potássio e calcário. Acta Scientiarum. Agronomy, v.27, n.2, p.261-268, 2005.

FRANÇA NETO, J. de B.; HENNING, A.A. Qualidade fisiológica de sementes de soja. Londrina: EMBRAPACNPSo, 1984. 39p. (EMBRAPA - CNPSo.Circular técnica, 9).

GALBIATTI, J.A.; BORGES, M.J.; BUENO, L.F.; GARCIA, A.; VIEIRA, R.D. Efeito de diferentes períodos de irrigação no desenvolvimento, produção e qualidade de sementes na cultura do milho (Zea mays L.). Engenharia Agrícola, v.24, n.2, p.301-308, 2004.

HEATHERLY, L.G. Drought stress and irrigation effects on germination of harvested soybean seed. Crop Sciense, v.33, n.4, p.777-781, 1993.

HENNING, A.A.; FRANÇA NETO, J.B. Secagem e armazenamento de sementes de soja. In: ARANTES, N.E.; SOUZA, P.I.M. (Ed.). Cultura da soja nos cerrados. Piracicaba: Potafós, 1993. p.437-463.

JACINTO, J.B.C.; CARVALHO, N.M. Maturação de sementes de soja. Científica, Jaboticabal, v.1, n.1, p.81-88, 1974.

KOLCHINSKI, E.M.; SCHUCH, L.O.B.; PESKE, S.T. Vigor de sementes e competição intra-específica em soja. Ciência Rural, v.35, n.6, p.1248-1256, 2005.

KRZYZANOWSKI, F.C.; GILIOLI, J.L.; MIRANDA, L.C. Produção de sementes nos cerrados In: ARANTES, N.E.; SOUZA, P.I.M. (Ed.).Cultura da soja nos cerrados. Piracicaba: Potafós, 1993. p.465-522.
LIMA， E.V.; CRUSCIOL， C.A.C.; CAVARIANI， C.; NAKAGAWA, J. Características agronômicas, produtividade e qualidade fisiológica da soja "safrinha" sob semeadura direta, em função da cobertura vegetal e da calagem superficial. Revista Brasileira de Sementes, v.31, n.1, p.6980, 2009.

MARCOS FILHO, J.; MIRANDA, M.A.C.; KOMATSU, Y.H. Época de semeadura e qualidade fisiológica de sementes de soja. In: SEMINÁRIO NACIONAL DE PESQUISA DE SOJA, 3., Campinas, 1984. Anais... Londrina: EMBRAPACNPSo, 1984. p.132.

MEDINA, P.F.; RAZERA, L.F.; MARCOS FILHO, J.; BORTOLETTO, N. Produção de sementes de cultivares precoces de soja em duas épocas e dois locais paulistas: II. Qualidade fisiológica. Bragantia, v.56, n.2, p.305-315, 1997.

MOTTA, I.S.; BRACCINI, A.L.; SCAPIM, C.A.; INOUE, M.H.; ÁVILA, M.R.; BRACCINI, M.C.L. Época de semeadura em cinco cultivares de soja. II. Efeito na qualidade fisiológica das sementes. Acta Scientiarum.Agronomy, v.24, n.5, p.1281-1286, 2002.

NAKAGAWA, J.; MACHADO, J.R.; ROSOLEM, C.A. Efeito da densidade de plantas e da época de semeadura na produção e qualidade de sementes de soja. Revista Brasileira de Sementes, v.8, n.3, p.99-112, 1986.

OLIVEIRA, A. Influência dos danos mecânicos ocorridos durante o beneficiamento sobre a qualidade fisiológica, sanitária e potencial de armazenamento de sementes de duas cultivares de soja. 1997. 90f. Dissertação (Mestrado) - Universidade Estadual Paulista, Jaboticabal.

PEIXOTO, C.P; CÂMARA, G.M.S.; MARTINS, M.C.; MARCHIORI, L.F.S.; GUERZONI, R.A.; MATTIAZZI, P. Épocas de semeadura e densidade de plantas de soja: I. Componentes da produção e rendimento de grãos. Scientia Agricola, v.57, n.1, p.89-96, 2000.

RASSINI, J.B.; LIN, S.S. Efeito de períodos de estiagens artificiais durante os estádios de desenvolvimento da planta no rendimento e qualidade da semente de soja [Glycine max (L.) Merrill]. Agronomia Sulriograndense, v.2, n.17, p.225237, 1981.

RODO, A.B.; PANOBIANCO, M.; MARCOS FILHO, J. Metodologia alternativa do teste de envelhecimento acelerado para sementes de cenoura. Scientia Agricola, v.57, n.2, p.289-292, 2000.

ROSSETO, C.A.V.; MARCOS FILHO, J. Comparação entre os métodos de envelhecimento acelerado e de deterioração controlada para avaliação da qualidade de sementes de soja. Scientia Agricola, v.52, n.1, p.123-131, 1995. 
SANTOS, V.L.M.; SILVA, R.F.; CARDOSO, A.A.; SEDYIAMA, T. Avaliação da produtividade e da qualidade das sementes de genótipos de soja [Glycine max (L.) Merrill], colhidas na maturação fisiológica e trinta dias após o ponto de colheita. Revista Brasileira de Sementes, v.18, n.1, p.5056, 1996.

SILVA, J.B.; LAZARINI, E.; SÁ, M.E. Avaliação de genótipos de soja em semeadura de inverno, em Selvíria, MS: produção e qualidade fisiológica de sementes. Revista Brasileira de Sementes, v.29, n.3, p.169-176, 2007.

SMICIKLAS, K.D.; MULLEN, R.E.; CARLSON, R.E.; KNAPP, A.D. Drought-induced stress effect on soybean seed calcium and quality. Crop Science, v.29, n.6, p.1519-1523, 1989.

TECNOLOGIAS de produção de soja - região central do Brasil 2009 e 2010. Londrina: Embrapa Soja: Embrapa Cerrados: Embrapa Agropecuária Oeste, 2008. 262p. (Embrapa Soja. Sistemas de Produção, 13).

TEKRONY, D.M.; EGLI, D.B.; BALLES, J. The effect of the field productions environment on soybean seed quality. In: HEBBLETHWAITE, P.D. (Ed.). Seed production. London: Butterworths, 1980. p.403-425.

TRAGNAGO, J.L.; BONETTI, L.P. Diferentes épocas de semeadura no rendimento e outras características de alguns cultivares de soja no Rio Grande do Sul. In: SEMINÁRIO NACIONAL DE PESQUISA DE SOJA, 3., 1984, Campinas. Anais... Londrina: EMBRAPA-CNPSo, 1984. p.57-69.
(EMBRAPA - CNPSo. Documentos, 7).

VIEIRA, R.D.; KRZYZANOWSKI, F.C. Teste de condutividade elétrica. In: KRZYZANOWSKI, F.C.; VIEIRA, R.D.; FRANÇA NETO, J.B. (Ed.). Vigor de sementes: conceitos e testes. Londrina: Abrates, 1999. cap. 4, p.1-26.

VIEIRA, R.D.; PAIVA AGUERO, J.A.; PERECIN, D. Electrical conductivity and field performance of soybean seeds. Seed Technology, v.21, p.15-24, 1999a.

VIEIRA, R.D.; PAIVA-AGUERO, J.A.; PERECIN, D.; BITTENCOURT, S.R.M. Correlation of electrical conductivity and other vigor tests with field emergence of soybean seedlings. Seed Science and Technology, v.27, p.67-75, 1999b.

VIEIRA, R.D.; SCAPPA NETO, A.; BITTENCOURT, S.R.M.; PANOBIANCO, M. Electrical conductivity of the seed soaking solution and soybean seedling emergence. Scientia Agricola, v.61, n.2, p.164-168, 2004.

VIEIRA, R.D.; TEKRONY, D.M.; EGLI, D.B. Effect of drough stress on soybean seed germination and vigor. Journal of Seed Technology, v.15, n.2, p.12-21, 1991.

VIEIRA.; R.D.; SEDYIAMA, T.; SILVA, R.F.; SEDYIAMA, C.S.; THIÉBAUT, J.T.L. Efeito do retardamento da colheita sobre a qualidade de sementes de soja cv. "UFV-2". Revista Brasileira de Sementes, v.4, n.2, p.9-22, 1982.

YALICH, R.W.; CREGAN, P.B. A field study of moisture content of soybean pods seeds after harvest maturity. Journal of Seed Technology, v.11, n.1, p.62-68, 1987. 